\title{
X-Ray Photoelectron Spectroscopic Studies of Polyquinazolones: An Assessment of the Degree of Cyclization
}

\author{
Hardy S. O. Chan, ${ }^{\dagger}$ T. S. Andy Hor, M. M. Sim, \\ K. L. TAN, ${ }^{*}$ and B. T. G. TAN* \\ Department of Chemistry and ${ }^{*}$ Department of Physics, \\ National University of Singapore, Kent Ridge, \\ Singapore 0511, Republic of Singapore
}

(Received April 11, 1990)

\begin{abstract}
Prepolymers of polyquinazolone have been prepared from 4,4'-diaminodiphenyl$3,3^{\prime}$-dicarboxylic acid and aromatic diacetoamido compounds by melt condensation. Optimum preparative conditions were established for each individual system on the basis of reduced viscosity and thermogravimetry (TG) results. The soluble prepolymers were converted to the quinazolone structure by thermal cyclization under two heating programmes. A significant amount of uncyclized carboxylic groups have been identified by X-ray photoelectron spectroscopy (XPS). Quantitative measurements of the $\mathrm{C}=\mathrm{O} / \mathrm{COOH}$ ratio at the surface of the resultant polymers have been carried out by XPS, which provide a reliable measure of the degree of cyclization. Comparison of XPS results with TG data indicates a direct correlation between degree of cyclization on the polymer surface and thermooxidative stability of the bulk polymer.

KEY WORDS Heat Resistant Polymer / Polyquinazolone / X-Ray

Photoelectron Spectroscopy / Thermogravimetry / Degree of Thermal

Cyclization / Thermooxidative Stability /
\end{abstract}

One of the major limitations of synthetic polymers is their poor thermooxidative stability compared with other materials, especially metals, alloys and ceramics. To overcome this problem as well as to meet the rapid development of atomic reactors and space aviation, a new generation of heat resistant polymers has been prepared during the past decades.

The attempt to synthesize polymers capable of withstanding prolonged exposure to elevated temperature, has been three pronged.

1. To improve the existing polymers by structural modification.

2. To devise new organic systems tailored to resist the effect of heat and oxidation.

3. To synthesize new classes of inorganic and semi-inorganic polymers of high thermal stability.

In the second mode of attack, the most fruitful of these three lines of research, a whole new generation of carbon-based polymers with inherently rigid chains have been developed. The polymers were prepared by incorporating highly stable rigid, carboxylic and/or heterocyclic ring systems directly into the polymer chain. An infinite variety of such structures is possible, and many have been synthesized. One of the most serious draw backs of heat resistant polymers is their insolubility and intractability conferred by the very structural features desirable for high thermal stability. In the case of the most promising heat resistant polymers such as polyimides, ${ }^{1-3}$ the most commercially successful of all the heat resistant polymers, polybenzimidazole, ${ }^{4}$ polyquinazolones, ${ }^{5}$ poly-

\footnotetext{
† To whom correspondence should be addressed.
} 
imidazolepyrrolones, ${ }^{6}$ and polyquinazolinediones, ${ }^{7}$ the synthesis involved a novel two steps process in which soluble and fabricable high molecular weight prepolymers were first prepared. Rigid stable rings were then formed by thermally or chemically induced cyclodehydration or cyclisation of reactive group attached to the prepolymer chain to give an insoluble, infusible and intractable polymer. This approach enabled films, fibres and coatings to be produced.

In our previous work on polyquinazolones, ${ }^{8}$ concurrent decarboxylation during the cyclization step was detected by differential thermal analysis (DTA) coupled with mass spectrometry (MS), which meant that the actual structure deviated from theory. This problem was also encountered in polyimides, ${ }^{9,10}$ where a controversy exists as to whether the imidization reaction goes to completion. We consider this a potentially very serious concern in the field of thermally stable polymer which has received too little attention. We have used in the past $\mathrm{TG}^{11}$ and elemental analysis ${ }^{12}$ in an attempt to quantify the degree of cyclization with limited success due mainly to the small relative weight change incurred in the conversion of prepolymer to the fully cyclised polyquinazolone. The disappearance of the NH band between $3000-3400 \mathrm{~cm}^{-1}$ in IR spectroscopy has also been used to monitor the degree of cyclization in polyquinazolones by the use of an internal reference peak. ${ }^{8}$ This, however, provides only a semi-quantitative assessment depending on an arbitrary internal reference which may give unreliable results. The usefulness of XPS for polymer characterization is well known ${ }^{13-16}$ and we would like to report in this communication recent XPS studies to determine more accurately the degree of cyclization in polyquinazolones and to correlate the results with thermooxidative stability assessed by TG.

\section{EXPERIMENTAL}

\section{Preparation of Monomers}

4,4'-Diaminodiphenyl-3,3'-dicarboxylic acid (BDC) (I) 4-diacetamidophenylene ( $p$-DAP) (II) and 4,4'-diacetamidodiphenyl methane (DADM) (III) shown in Figure 1 were prepared according to methods previously reported. ${ }^{17,18}$ For $\mathrm{BCD}$; yield $=64 \%, \mathrm{mp} 302^{\circ} \mathrm{C}$ (with decomposition), lit. $\mathrm{mp}^{17} 300^{\circ} \mathrm{C}$. For $p$-DAP; yield $=69 \%$, mp $305^{\circ} \mathrm{C}$, lit. $\mathrm{mp}^{19} 303^{\circ} \mathrm{C}$. For DADM; yield $=71 \%, \mathrm{mp} 227^{\circ} \mathrm{C}$, lit. $\mathrm{mp}^{19}$ $227-228^{\circ} \mathrm{C}$.

\section{Preparation of Prepolymer}

Quinazolone prepolymers were prepared as

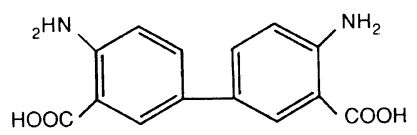

4,4'-diaminodiphenyl-3,3'-dicarboxylic acid (BDC)

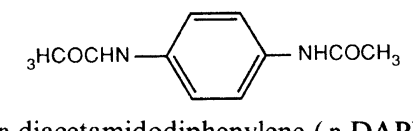

$$
p \text {-diacetamidodiphenylene ( } p \text {-DAP) }
$$

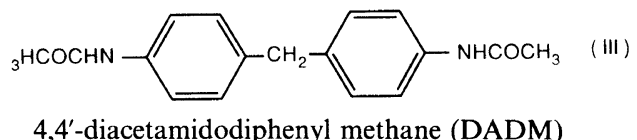

4,4'-diacetamidodiphenyl methane (DADM)

Figure 1. Structures of monomers.
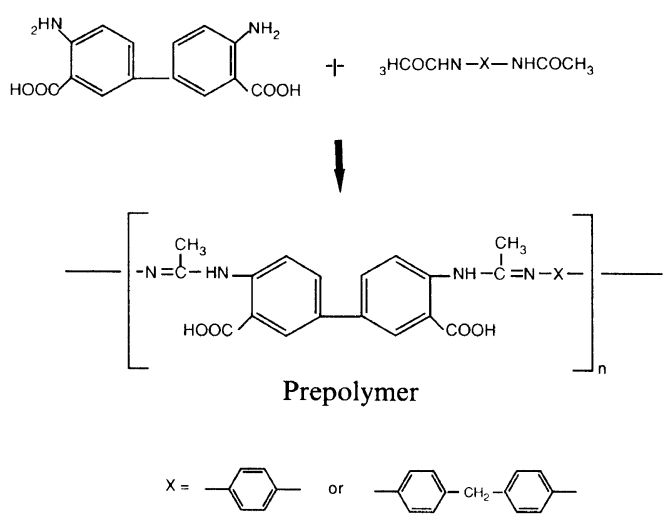

Figure 2. General structure of the prepolymer. 
previously reported. ${ }^{18}$ Equimolar amounts of BDC $(0.005 \mathrm{~mol})$ and each comonomer $(0.005$ mol) were mixed thoroughly together and the polymerization was effected by melt condensation under a nitrogen atmosphere at $255^{\circ} \mathrm{C}$. In the present work the polymerization was carried out for 1,2 , and $3 \mathrm{~h}$, respectively to study the effect of polymerization time. The structure of the prepolymer is given in Figure 2. $\mathrm{DP}_{\mathrm{p}}(2)$ (subscript $\mathrm{p}$ to indicate prepolymer; figure in bracket indicates polymerization time in hour) was obtained in $91 \%$ yield as a dark green glassy material for both cyclization conditions. Calculated \% composition for $\mathrm{DP}_{\mathrm{p}}$ prepolymer $\left(\mathrm{C}_{24} \mathrm{H}_{20} \mathrm{~N}_{4} \mathrm{O}_{4}\right): \mathrm{C}, 67.3 \% ; \mathrm{H}$, $4.7 \%$; N, $13.1 \%$; O, 14.9\% (by difference). Found for $\mathrm{DP}_{\mathrm{p}}(2)$ : $\mathrm{C}, 68.3 \% ; \mathrm{H}, 5.0 \% ; \mathrm{N}$, $12.9 \%$; O, $13.8 \%$ (by difference). Prepolymer $\mathrm{DADM}_{\mathrm{p}}$ was obtained as a grey glassy material in $70.8 \%$ yield. Calculated for $\left(\mathrm{C}_{31} \mathrm{H}_{26} \mathrm{~N}_{4} \mathrm{O}_{5}\right)$ : $\mathrm{C}, 71.8 \%$; H, 5.1\%; N, 10.8\%; O, $12.3 \%$. Found for DADM $(2): C, 71.0 \% ; H, 5.5 \% ; N$, $10.6 \%$; O, $12.9 \%$.

\section{Viscosity Measurement}

In order to determine the optimum polymerization time the reduced viscosities of the prepolymers obtained for different periods were measured in distilled $N$-methyl-2-pyrrolidone (NMP) (1\% solution by weight) at $25 \pm 0.03^{\circ} \mathrm{C}$ using an Ostwald viscometer (bore

Table I. Viscosity measurements for prepolymers $\mathrm{DAP}_{\mathrm{p}}$ and $\mathrm{DADM}_{\mathrm{p}}$

\begin{tabular}{lcc}
\hline \multicolumn{1}{c}{ System $^{\mathrm{a}}$} & $\begin{array}{c}\text { Flow time, } \\
t_{\mathrm{p}} / \mathrm{s}\end{array}$ & $\eta_{\mathrm{sp}}^{\mathrm{b}}$ \\
\hline $\operatorname{DAP}_{\mathrm{p}}(1)$ & 58.88 & 0.0723 \\
$\operatorname{DAP}_{\mathrm{p}}(2)$ & 60.79 & 0.1071 \\
$\operatorname{DAP}_{\mathrm{p}}(3)$ & 58.81 & 0.0710 \\
$\operatorname{DADM}_{\mathrm{p}}(1)$ & 56.21 & 0.0237 \\
$\operatorname{DADM}_{\mathrm{p}}(2)$ & 59.93 & 0.0914 \\
$\operatorname{DADM}_{\mathrm{p}}(3)$ & 57.14 & 0.0416
\end{tabular}

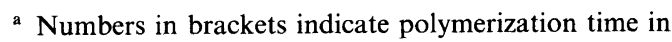
hour.

${ }^{\mathrm{b}} \eta_{\mathrm{sp}}=\left(t_{\mathrm{p}}-t_{\mathrm{s}}\right) / t_{\mathrm{s}}$. Average flow time for solvent $\left(t_{\mathrm{s}}\right)=$ $54.91 \mathrm{~s}$. diameter $0.4 \mathrm{~mm}$ ). The flow times reported are averages of 6 repeated determinations to an accuracy of $\pm 0.02 \mathrm{~s}$. The results are summarized in Table I.

\section{Preparation of Polyquinazolone (Cyclization)}

The optimum prepolymers determined by viscosity measurements, $\operatorname{DP}_{p}(2)$ and $\operatorname{DADM}_{p}(2)$ were dissolved in NMP ( $20-30 \%$ by weight) and the viscous polymer solution was deposited onto a thin glass slide as a thin viscous film. The prepolymer was then cyclised under vacuum in a tube furnace under two different regimes: Condition (A); $30 \mathrm{~min}$ at $250^{\circ} \mathrm{C}$ followed by $20 \mathrm{~min}$ at $280^{\circ} \mathrm{C}$ followed by $40 \mathrm{~min}$ at $305^{\circ} \mathrm{C}$, and condition (B); $90 \mathrm{~min}$ at $305^{\circ} \mathrm{C}$. The structures of the ideal and partially cyclized polyquinazolone are given in Figure 3 . Calculated for $\mathrm{DP}_{\mathrm{c}}(\mathrm{A})\left(\mathrm{C}_{24} \mathrm{H}_{16} \mathrm{~N}_{4} \mathrm{O}_{2}\right)$ : C, $73.5 \% ; \mathrm{H}, 4.1 \% ; \mathrm{N}, 14.3 \%$; O, 8.1\% . (by difference). Found: C, 73.8\%; H, 4.8\%; N, $14.1 \% ; \mathrm{O}, 7.3 \%$. Found for $\mathrm{DP}_{\mathrm{c}}(\mathrm{B}): \mathrm{C}, 75.0 \%$; $\mathrm{H}, 4.3 \%$; N, $14.5 \%$; O, 6.2\%. Calculated for $\operatorname{DADM}_{c}(\mathrm{~A})\left(\mathrm{C}_{31} \mathrm{H}_{22} \mathrm{~N}_{4} \mathrm{O}_{2}\right): \mathrm{C}, 77.1 \% ; \mathrm{H}$, $4.6 \% ; \mathrm{N}, 11.6 \%$; O, 6.6\% (by difference). Found: C, $77.1 \% ; \mathrm{H}, 5.2 \% ; \mathrm{N}, 12.1 \% ; \mathrm{O}$, $5.7 \%$. Found for $\mathrm{DM}_{\mathrm{c}}(\mathrm{B}): \mathrm{C}, 78.3 \% ; \mathrm{H}, 5.0 \%$; $\mathrm{N}, 11.8 \%$; O, $4.9 \%$.

\section{Elemental Analysis}

The elemental analyses were conducted by

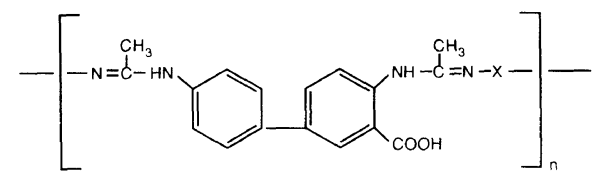

Incomplete cyclisation

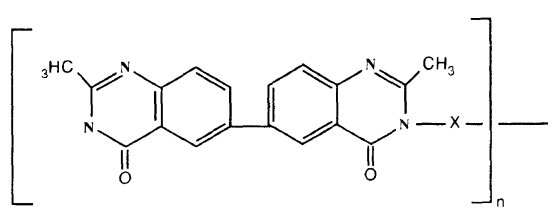

Polyquinazolone

Figure 3. Polyquinazolone: complete vs. incomplete cyclization. 
the Microanalytical Laboratory using a PerkinElmer model 240C C, H, N analyzer.

\section{$X$-Ray Photoelectron Spectroscopy}

In the case of the prepolymers, the powders were mounted onto a standard VG holder by double-sided Scotch tape. For the polyquinazolones, cyclization was carried out in-situ on the sample holder under the optimum conditions and transferred immediately into the vacuum chamber $\left(\approx 10^{-7}\right.$ Torr $)$ in the XPS machine to minimise contamination. Core levels spectra were obtained on a VG ECSA/SIMSLAB MK II spectrometer using $\mathrm{Mg}-K_{\alpha}$ radiation, operating on a fixed retardation ratio of 40 . The binding energies were referred to the hydrocarbon component in the $\mathrm{C}_{1 \mathrm{~s}}$ envelope, defined at $285.0 \mathrm{eV}$ to compensate for surface charging. Surface stoichiometries were obtained from peak area ratios corrected with appropriate experimentallydetermined sensitivity factors. Deconvolution of overlapping spectral components were performed on VG softwares.

\section{Thermogravimetry}

TG studies were performed on a du Pont 9900 thermal analyzer under a dynamic air flow of $75 \mathrm{~cm}^{3} \mathrm{~min}^{-1}$ at a linear heating rate of $10^{\circ} \mathrm{C} \mathrm{min}^{-1}$ from room temperature to $700^{\circ} \mathrm{C}$. The samples were run in powder form of weight $\approx 5 \mathrm{mg}$.

\section{RESULTS AND DISCUSSION}

\section{Viscosity}

From the results shown in Table I, it can be seen that the optimum polymerization time is $2 \mathrm{~h}$ for both $\mathrm{DAP}_{\mathrm{p}}$ and $\mathrm{DADM}_{\mathrm{p}}$ based on their specific viscosities which can be used as an indication of molecular weight of the prepolymers. Further determination of viscosity average molecular weight for the prepolymers from intrinsic viscosity measurements was not possible due to the unavailability of the constants $\mathrm{K}$ and $\alpha$ in the Mark-Houwink equaion.

\section{Thermogravimetry}

The TG thermograms are shown in Figures 4- 6 and the results are summarized in Table II. It can be seen in Figure 4 that both the $\operatorname{DAP}_{p}(1)$ and $\operatorname{DAP}_{p}(3)$ exhibit lower thermal stability than the corresponding $\operatorname{DAP}_{p}(2)$. The stability of a polymer, amongst other considerations, is related to its molecular weight.

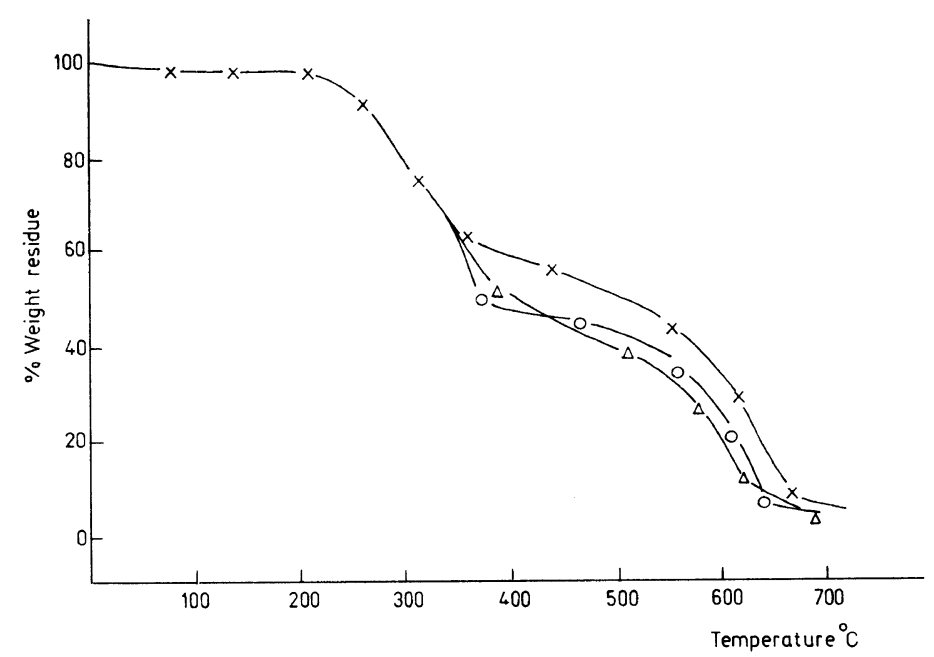

Figure 4. TG thermogram of $\operatorname{DAP}_{p}(1),-\mathrm{O}^{-} \mathrm{O}^{-}$; $\mathrm{DAP}_{\mathrm{p}}(2),-\triangle-\triangle-$; $\mathrm{DAP}_{\mathrm{p}}(3),-x-x-$. 
XPS of Polyquinazolones

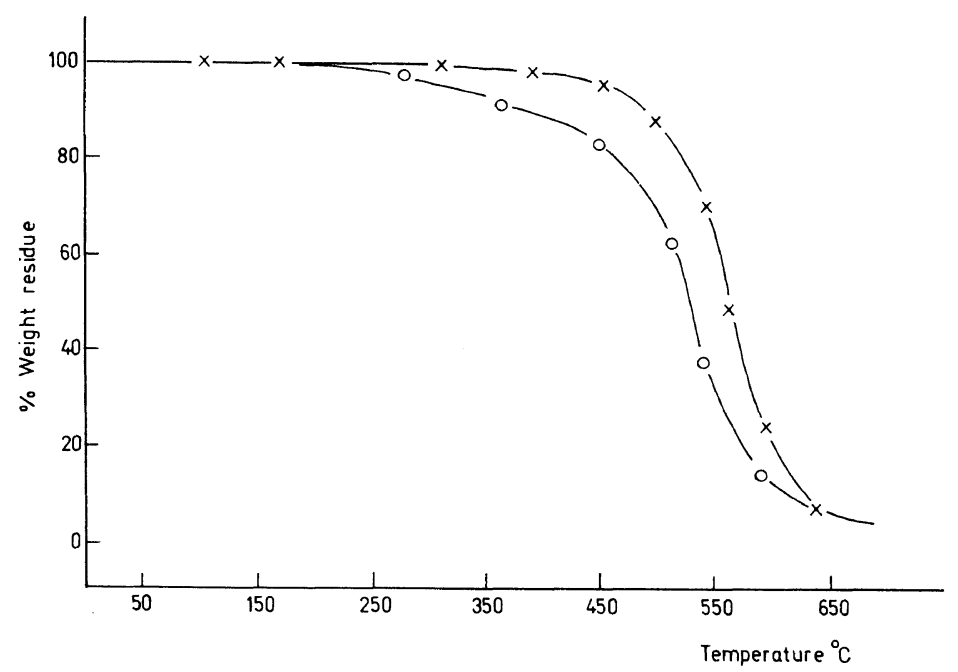

Figure 5. TG thermogram of $\mathrm{DAP}_{\mathrm{p}}$ cyclized under programme $A,-x-x-$. TG thermogram of $\mathrm{DAP}_{\mathrm{p}}$ cyclized under programme $\mathrm{B},-\mathrm{O}-\mathrm{O}-$.

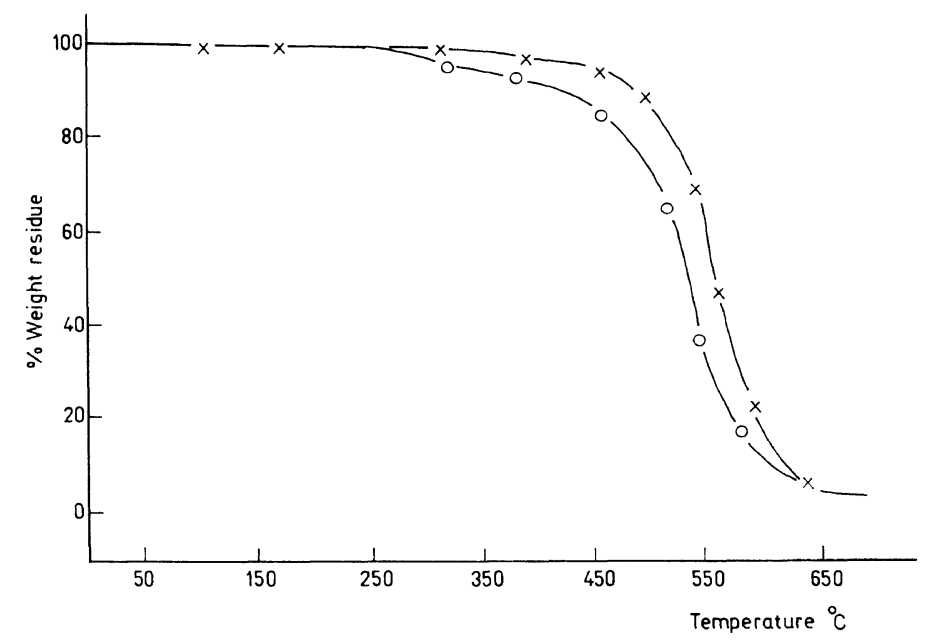

Figure 6. TG thermogram of $\mathrm{DAP}_{\mathrm{c}},-\mathrm{x}-\mathrm{x}-\mathrm{DADM}_{\mathrm{c}},-\mathrm{O}-\mathrm{O}-$.

This is particularly relevant when we compare prepolymers of similar structures. The TG results are in good agreement with the viscosity data. It can be concluded that for the present series of polyquinazolones, the optimum polymerization time is around two hours.

The thermograms (Figure 5) and the thermal index $\left(T_{50 \%}\right)$ in Table II of the polyqinazolone $\mathrm{DAP}_{c}$ cyclized under different heating pro- grammes show clearly that programme (A) produced more thermooxidatively stable polymers. It can be seen from Figure 6 that $\mathrm{DAP}_{c}$ has a higher overall stability than $\mathrm{DADM}_{\mathrm{c}}$. The $-\mathrm{CH}_{2}-$ group may act as a weak link during the degradation of the polymer.

$X P S$

The $\mathrm{O}_{1 \mathrm{~s}}, \mathrm{~N}_{1 \mathrm{~s}}$, and $\mathrm{C}_{1 \mathrm{~s}}$ core spectra for the 
prepolymers and cyclized polymers are compared in Figures 7-9 and the surface stoichiometries have been compared with the bulk composition in Table III. The surface

Table II. Thermal stability indices of pre- and cyclized DAP and DADM

\begin{tabular}{lcc}
\hline \multicolumn{1}{c}{ System $^{\mathrm{a}}$} & $\mathrm{pdt}\left({ }^{\circ} \mathrm{C}\right)^{\mathrm{b}}$ & $T_{50 \%}{ }^{\mathrm{c}}$ \\
\hline $\mathrm{DAP}_{\mathrm{p}}(1)$ & $\approx 200$ & 395 \\
$\operatorname{DAP}_{\mathrm{p}}(2)$ & $\approx 200$ & 495 \\
$\operatorname{DAP}_{\mathrm{p}}(3)$ & $\approx 200$ & 369 \\
$\operatorname{DADM}_{\mathrm{p}}(1)$ & $\approx 200$ & 372 \\
$\operatorname{DADM}_{\mathrm{p}}(2)$ & $\approx 200$ & 430 \\
$\mathrm{DADM}_{\mathrm{p}}(3)$ & $\approx 200$ & 360 \\
DAP $_{\mathrm{c}}(\mathrm{A})$ & $\approx 200$ & 526 \\
$\mathrm{DAP}_{\mathrm{c}}(\mathrm{B})$ & $\approx 350$ & 558 \\
DADM $_{\mathrm{c}}(\mathrm{A})$ & $\approx 200$ & 500 \\
DADM $_{\mathrm{c}}(\mathrm{B})$ & $\approx 275$ & 534 \\
\hline a & Numbers in brackets indicate polymerization time in \\
hour. Letters in brackets indicate different cyclization \\
programes (A) and (B). \\
b pdt=the temperature at which the first observable \\
weight loss occurs in dynamic TG. \\
c $T_{50 \%}=$ temperature at which 50\% weight loss has \\
occurred in dynamic TG.
\end{tabular}

stoichiometries of the elements are calculated based on the peak area of the corresponding XPS peaks corrected with the appropriate sensitivity factor referenced to carbon which has a value of 1.0. The high carbon content found on the surface can be attributed to hydrocarbon contamination and the low oxygen may be due to concurrent decarboxylation during cyclization. The chemical shifts and $\%$ area ratios of the various core levels and

Table III. Comparison of surface and bulk stoichimetries

\begin{tabular}{|c|c|c|c|c|c|c|c|}
\hline \multirow{2}{*}{ Sample } & \multicolumn{4}{|c|}{ Bulk } & \multicolumn{3}{|c|}{ Surface } \\
\hline & $\mathrm{C}$ & $\mathrm{H}$ & $\mathrm{N}^{\mathrm{a}}$ & $\mathrm{O}$ & $\mathrm{C}$ & $\mathrm{N}$ & $\mathrm{O}$ \\
\hline $\operatorname{DAP}_{p}(2)$ & 24.8 & 21.8 & 4.0 & 3.8 & 25.0 & 4.0 & 4.1 \\
\hline $\operatorname{DADM}_{p}(2)$ & 31.0 & 28.9 & 4.0 & 4.3 & 32.3 & 4.0 & 4.1 \\
\hline $\operatorname{DAP}_{c}(\mathrm{~A})$ & 24.4 & 19.0 & 4.0 & 1.81 & 25.1 & 4.0 & 1.86 \\
\hline $\mathrm{DAP}_{\mathrm{c}}(\mathrm{B})$ & 24.0 & 16.5 & 4.0 & 1.49 & 24.8 & 4.0 & 1.51 \\
\hline $\mathrm{DADP}_{\mathrm{p}}(\mathrm{A})$ & 29.8 & 23.3 & 4.0 & 1.78 & 29.2 & 4.0 & 1.80 \\
\hline $\operatorname{DADM}_{\mathrm{p}}(\mathrm{B})$ & 31.1 & 24.8 & 4.0 & 1.45 & 31.6 & 4.0 & 1.49 \\
\hline
\end{tabular}

a The atomic ratios are normalized to $\mathrm{N}_{4.0}$.

Table IV. XPS data for pre- and cyclized polymers of DAP and DADM

\begin{tabular}{|c|c|c|c|c|c|c|}
\hline \multirow{2}{*}{$\begin{array}{l}\text { XPS core } \\
\text { level }\end{array}$} & \multicolumn{3}{|c|}{$\operatorname{DAP}_{p}$} & \multicolumn{3}{|c|}{$\mathrm{DADM}_{\mathrm{p}}$} \\
\hline & $\mathrm{BE}(\mathrm{eV})$ & $\mathrm{BE}$ & Relative \% & $\mathrm{BE}(\mathrm{eV})$ & $\mathrm{BE}$ & Relative \% \\
\hline \multirow[t]{3}{*}{$\mathrm{C}_{1 \mathrm{~s}}$} & 285.0 & & 77.3 & 285.0 & & 83.6 \\
\hline & 286.4 & 1.4 & 12.6 & 286.4 & 1.4 & 9.2 \\
\hline & 289.1 & 4.1 & 9.2 & 289.1 & 4.1 & 6.9 \\
\hline \multirow[t]{2}{*}{$\mathrm{N}_{1 \mathrm{~s}}$} & 399.7 & & 49.6 & 399.7 & & 45.7 \\
\hline & 400.8 & 1.1 & 50.2 & 400.8 & 1.1 & 43.9 \\
\hline \multirow[t]{3}{*}{$\mathrm{O}_{1 \mathrm{~s}}$} & 532.1 & & 46.4 & 532.1 & & 48.6 \\
\hline & 533.3 & 1.2 & 45.5 & 533.3 & 1.2 & 47.2 \\
\hline & 535.1 & 2.7 & 7.7 & 535.1 & 2.7 & 4.2 \\
\hline \multirow{5}{*}{$\mathrm{C}_{1 \mathrm{~s}}$} & & $\mathrm{DAP}_{\mathrm{c}}$ & & & $\mathrm{ADN}$ & \\
\hline & 285.0 & & 80.0 & 285.0 & & 84.9 \\
\hline & 286.4 & 1.4 & 9.2 & 286.4 & 1.4 & 7.3 \\
\hline & 287.9 & 2.9 & 7.2 & 287.9 & 2.9 & 5.2 \\
\hline & 289.1 & 4.1 & 1.4 & 289.1 & 4.1 & 1.4 \\
\hline \multirow[t]{2}{*}{$\mathrm{N}_{1 \mathrm{~s}}$} & 399.6 & & 50.2 & 399.7 & & 50.6 \\
\hline & 400.7 & 1.1 & 49.7 & 400.8 & 1.1 & 49.4 \\
\hline \multirow[t]{2}{*}{$\mathrm{O}_{1 \mathrm{~s}}$} & 532.3 & & 82.8 & 532.2 & & 78.2 \\
\hline & 533.7 & 1.4 & 16.6 & 533.7 & 1.4 & 21.8 \\
\hline
\end{tabular}




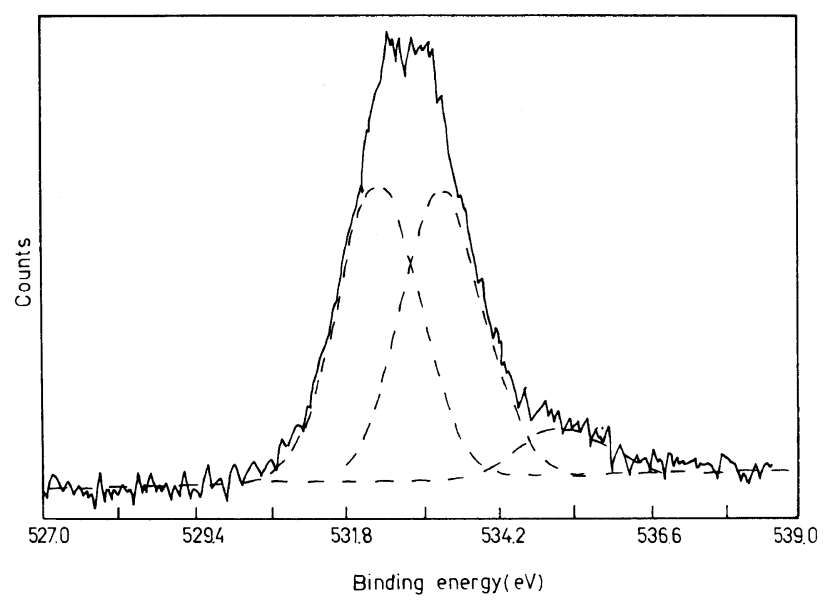

(a)

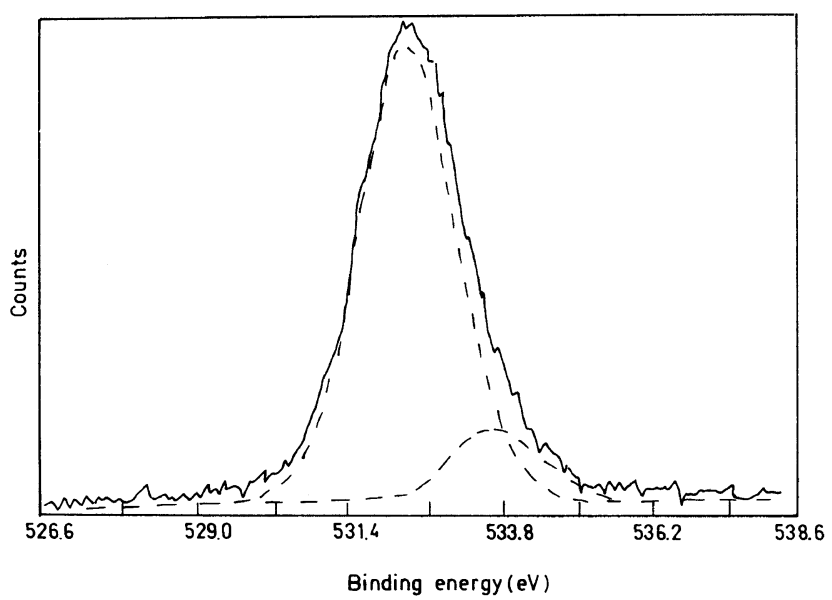

(b)

Figure 7. Curve fitted $\mathrm{O}_{1 \mathrm{~s}}$ spectrum of (a) $\mathrm{DAP}_{\mathrm{p}}$ and (b) $\mathrm{DAP}_{c}$.

their deconvoluted components for both the DAP and DADM systems are summarized in Table IV. For the prepolymer, there should theoretically be two peaks of equal area in the $\mathrm{O}_{1 \mathrm{~s}}$ spectrum, i.e., the $\mathrm{C}=\mathrm{O}(532.1 \mathrm{eV})$ and the $\mathrm{C}-\mathrm{O}(533.3 \mathrm{eV})$ in the COOH moiety in $\mathrm{DAP}_{\mathrm{p}}$. We have attributed the highest binding energy peak at $535.1 \mathrm{eV}$ to the presence of free water. This peak disappeared after the prepolymer was left in the desiccator for three days and also after cyclization. This free water has also been observed in low density polyethylene. ${ }^{20}$
The $\mathrm{N}_{1 \mathrm{~s}}$ spectrum consists of two peaks of which implies that two different environments are present. The nitrogen which is attached to the double bond in the structure - $\mathrm{C}-\mathrm{NH}-$ $\mathrm{C}\left(\mathrm{CH}_{3}\right)=\mathrm{N}-\mathrm{C}-$ has been assigned the lower $\mathrm{BE}(399.7 \mathrm{eV})$ as compared to the nitrogen attached to the hydrogen at $400.8 \mathrm{eV}$. Although the double bond can tautomerize between the two nitrogens, the rate at room temperature is likely to be much lower than the photoelectron emission process which is in the region of $10^{-17}-10^{-14} \mathrm{~s}$. Hence, two distinguishable 


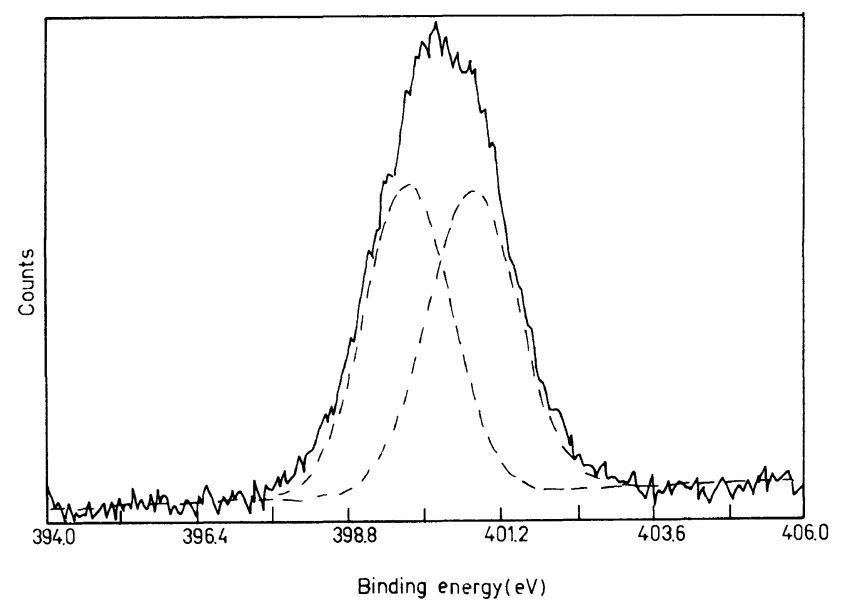

(a)

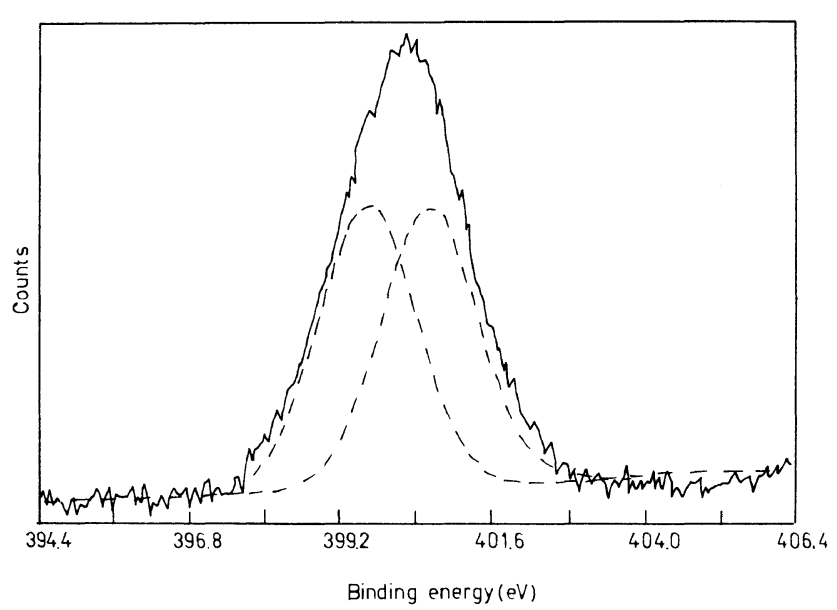

(b)

Figure 8. Curve fitted $\mathrm{N}_{1 \mathrm{~s}}$ spectrum of (a) $\mathrm{DAP}_{\mathrm{p}}$ and (b) $\mathrm{DAP}_{\mathrm{c}}$.

peaks are observed. The peak at $285 \mathrm{eV}$ in the $\mathrm{C}_{1 \mathrm{~s}}$ spectrum corresponds to the $\mathrm{C}-\mathrm{C}, \mathrm{C}-\mathrm{H}$, and possibly $\mathrm{N}-\mathrm{C}$ functionalities. The next peak at a shift of $1.4 \mathrm{eV}$ can be attributed to $\mathrm{C}-\mathrm{O}$ (from surface oxidation) and $\mathrm{N}-\mathrm{C}=\mathrm{N}$ functionalities. The highest binding energy peak at $289.1 \mathrm{eV}$ is assigned to the carbon in the $\mathrm{COOH}$ group. It should be noted that the observation and interpretation made for the $\mathrm{O}_{1 \mathrm{~s}}, \mathrm{~N}_{1 \mathrm{~s}}$, and $\mathrm{C}_{1 \mathrm{~s}}$ spectra of $\mathrm{DADM}_{\mathrm{p}}$ are similar to that of DAP $_{p}$.

For the cyclised polymers, the $\mathrm{N}_{1 \mathrm{~s}}$ spectrum remained basically unchanged. Both the $\mathrm{O}_{1 \mathrm{~s}}$ and $\mathrm{C}_{1 \mathrm{~s}}$, however, show significant differences which provide further information about the cyclization process. Comparison of Figures $7 \mathrm{a}$ and $b$ indicate a large decrease but not total disappearance of the lower binding energy $\mathrm{C}-\mathrm{O}$ component upon cyclization. It can be seen from Figure $9 b$ that for $\mathrm{DAP}_{c}$ the $\mathrm{COOH}$ peak in the $\mathrm{C}_{1 \mathrm{~s}}$ envelope has decreased considerably and an extra major component is observed at $289.7 \mathrm{eV}$ which can be attributed to the $\mathrm{C}=\mathrm{O}$ functionality specific to the polyquinazolone 


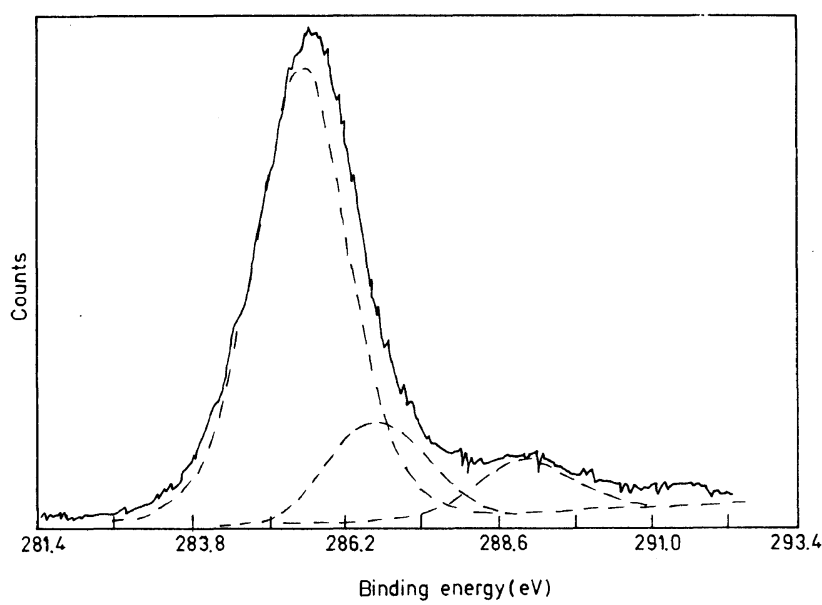

(a)

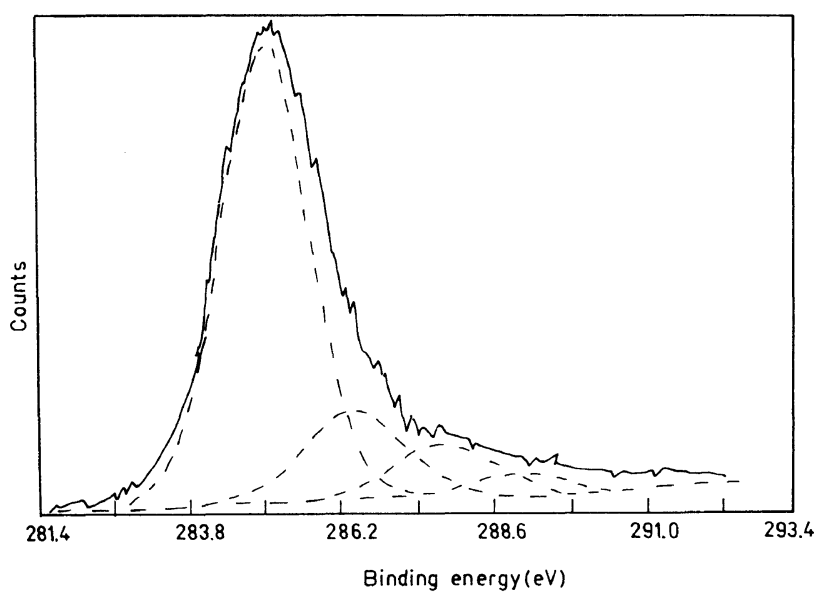

(b)

Figure 9. Curve fitted $C_{1 s}$ spectrum of (a) $\operatorname{DAP}_{p}$ and (b) $\mathrm{DAP}_{c}$.

structure. However, the presence of the $\mathrm{C}-\mathrm{O}$ and $\mathrm{COOH}$ peaks, no matter how small, suggests incomplete cyclization due to unreacted $\mathrm{COOH}$ group in addition to the decarboxylation suggested by the low oxygen content in both the elemental analysis and XPS surface stoichiometries in this work and DTA/MS studies previously reported. ${ }^{8}$ Table $\mathrm{V}$ gives the $\mathrm{C}=\mathrm{O} / \mathrm{COOH}$ ratios for the various polyquinazolones prepared under different cyclization conditions and their thermal data. The results clearly indicate that this quantity can be used as a more accurate measure of the degree of cyclization of the polyquinazolones than other available techniques. It is important to note that although the degree of cyclization data obtained has been limited to the surface, this quantity correlates directly with the bulk thermooxidative stability of the present series of polymers. Moreover, many forms of degradation initiate at the surface of the polymer before significant damages occur in the bulk. It can be seen that the more fully cyclized the polyquinazolone, the better its high 
Table V. Comparison of $\mathrm{C}=\mathrm{O} / \mathrm{COOH}$ ratio and thermal stability of cyclized polymer $\mathrm{DAP}_{\mathrm{c}}$ and $\mathrm{DADM}_{\mathrm{c}}$

\begin{tabular}{lcc}
\hline $\begin{array}{c}\text { Polymer } \\
\text { system }\end{array}$ & $\mathrm{C}=\mathrm{O} / \mathrm{COOH}$ & $T_{50 \%}\left({ }^{\circ} \mathrm{C}\right)$ \\
\hline $\operatorname{DAP}_{\mathrm{c}}(\mathrm{A})$ & 5.1 & 558 \\
$\operatorname{DAP}_{\mathrm{c}}(\mathrm{B})$ & 4.5 & 526 \\
$\mathrm{DADM}_{\mathrm{c}}(\mathrm{A})$ & 4.6 & 534 \\
$\mathrm{DADM}_{\mathrm{c}}(\mathrm{B})$ & 4.0 & 500 \\
\hline
\end{tabular}

a Letters in brackets indicate different cyclization programmes (A) and (B).

temperature performance. The ultimate goal in the area of heat resistant polymers must therefore be the ability to synthesize polymers with the ideal structure.

\section{CONCLUSIONS}

XPS has provided a rapid and accurate means of assessing quantitatively the degree of cyclization in polyquinazolones, a parameter vital to the preparation of heat resistant polymers involving a prepolymer step and which so far has not been determined to any degree of accuracy. We believe that the cyclization process should be studied and characterized more thoroughly in order to achieve a higher degree of cyclization which, based on the results reported in this paper, can be quantitatively determined by XPS. A more fully cyclised ring system would no doubt extract even better high temperature performance from some of the already commercially successful heat resistant polymers.

\section{REFERENCES}

1. C. E. Sroog, A. L. Endrey, S. V. Abramo, C. E. Berr, W. M. Edward, and K. L. O'liver, J. Polym. Sci., A, 3, 1373 (1965)

2. K. Kurita, H. Itoh, and Y. Iwakura, J. Polym. Sci., Polym. Chem. Ed., 17, 1187 (1979).

3. K. Iwata, M. Ogasáwara, and S. Hara, Makromol. Chem., 179 (5), 1361 (1978).

4. Y. Iwakura, K. Uno, and Y. Imai, J. Polym. Sci., A, 2, 2605 (1964).

5. A. Ghafoor and R. H. Still, J. Appl. Polym, Sci., 21, 2905 (1977).

6. V. L. Bell and G. F. Pezdirtz, J. Polym. Sci., B, 3, 977 (1965).

7. N. Yoda, K. Ikeda, M. Kurihara, S. Tohyama, and R. Nakariski, J. Polym. Sci., A, 5, 2359 (1967).

8. H. S. O. Chan and R. H. Still, J. Appl. Polym. Sci., 22, 2713 (1978).

9. S. D. Bruck, Polymer, 6, 49 (1965).

10. H. J. Leary, Jr. and D. S. Campell, Surface and Interface Analysis, 1, No. 3, 75 (1979).

11. H. S. O. chan and J. R. Lustry, J. Macromol. Sci. Chem., A, 23, 9, 1057 (1986).

12. H. S. O. Chan and R. H. Still, J. Appl. Polym. Sci., 22, 2187 (1978).

13. T. A. Furstch, L. T. Taylor, T. W. Fritz, and E. Khor, J. Polym. Sci., Polym. Chem. Ed., 20, 1287 (1982).

14. D. T. Clark, D. B. Adams, A. Dilks, J. Peeling, and H. R. Thomas, J. of Electron Spectroscopy and Related Phenomena, 8, 51 (1976).

15. M. M. Millard, in "Industrial Applications of Surface Analysis, L. A. Casper and C. J. Powell, Ed., ACS Symposium Series, 1982, Chapter 8.

16. D. Briggs, in "Practical Surface Analysis by Auger and X-Ray Photoelectron Spectroscopy, D. Briggs and M. P. Seah, Ed., John Wiley and Sons New York, N.Y., 1983, Chapter 9.

17. M. Kurihara and N. Yoda, Bull. Chem. Sci. Jpn., 40, 2429 (1967).

18. H. S. O. Chan, PhD thesis, Victoria University of Manchester (1975).

19. "Dictionary of Organic Compounds," 4th ed, Eyre and Spottiswoode, Condow, 1965.

20. D. T. Clark and W. J. Feast, J. Macromol. Sci. Revs. Macromol. Chem., C, 12 (2), 191 (1975). 